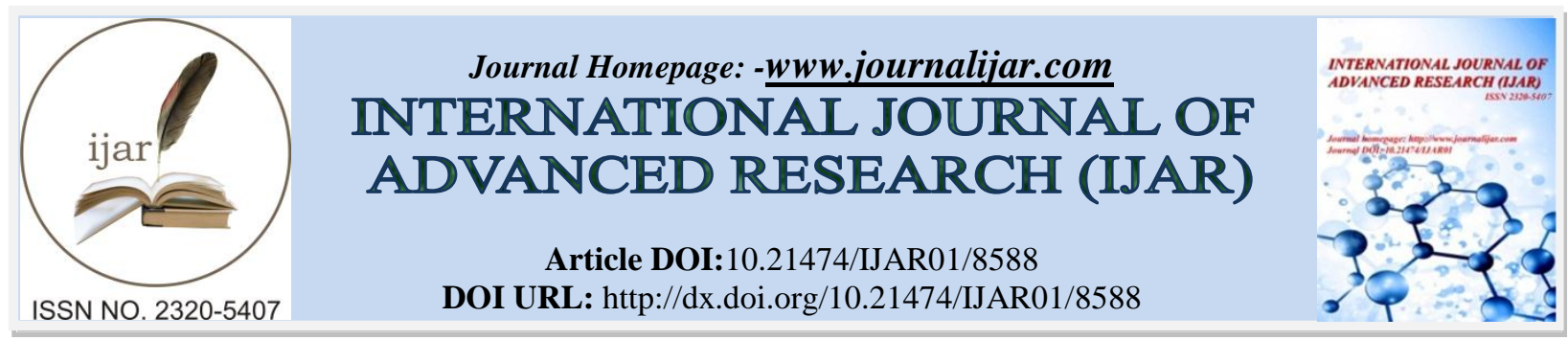

RESEARCH ARTICLE

\title{
VON WILLEBRAND DISEASE: A REVIEW OF 2 CASE REPORTS.
}

\section{Udaykiranraju Kallepalli ${ }^{1}$ and Niveditha Ragiri ${ }^{2}$.}

1. Junior Resident Department of General Medicine, Siddhartha Medical College, Gunadala, Vijayawada, Andhra Pradesh, India, 305 Prudvi Apartment, Lotus LandMark Sector One, Kedareswarapeta, Vijayawada- 520003, Andhra Pradesh, India.

2. Associate Professor, Department of General Medicine ,Siddhartha Medical College, Gunadala, Vijayawada.520008.

\section{Manuscript Info}

(..........................

Manuscript History

Received: 14 December 2018

Final Accepted: 16 January 2019

Published: February 2019

Key words:-

Von Willebrand Disease, Von

Willebrand Factor.
Abstract

VWD is an inherited bleeding disorder. Von Willebrand Factor(VWF) levels are decreased along with normal or decreased factor viii levels. Clinical symptoms are "platelet-like"bleeding and bleeding similar to factor viii deficiency bleeding. Bleeding can become life threatening either from the strategic location of bleed or the amount of blood loss or the complications arising from the massive blood loss. Treatment modalities include desmopressin (DDAVP) and replacement of VWF.The aim of this report is to make health professionals aware of this possibility that could be in operating in bleeding patient.

Copy Right, IJAR, 2019,. All rights reserved.

\section{Introduction:-}

VWD is an inherited bleeding disorder. Prevalence in laboratory data is around $1 \%$ but prevalence among clinically symptomatic individuals is around $0.1 \%$ of population. VWF functions as major adhesion molecule that tethers the platelet to the exposed sub-endothelium. Another function of VWF is to bind factor viii and thereby prolongs its half-life in circulation. The symptoms of VWD are mostly platelet like except in more severe VWD when the factor viii is low enough to produce symptoms similar to those found in factor viii deficiency (hemophilia A). Bleeding symptoms are very uncommon in infancy and usually manifest later in childhood with excessive bruising and epistaxis. Menorrhagia is a common manifestation of VWD. Although the inheritance of VWD is autosomal, many factors modulate both VWF levels and bleeding symptoms. These include blood type, thyroid hormone status, race, stress, exercise, and hormonal (both endogenous and exogenous) influences.

\section{Case Reports:-}

\section{Case 1:-}

A 15-year-old female patient was admitted to ward on presenting in out -patient department with menorrhagia and unstable hemodynamicson presentation. There waspast history of menorrhagia during last 10 months prior to this presentation since menarche at 15 years of age with menstrual flow pattern of heavy menstrual bleeding for initial 6 days of menstrual flow and spotting for another 6 days of menstrual flow past history of recurrent spontaneous nose bleeds starting at 4 years of age lasting up to 10 years of age, recurrent spontaneous gum bleeds starting from around 10 years of age until 15 years of age and history of excess bleeding from skin abrasion wounds from early childhood. However, there is no history of joint swelling during contact sports.

Corresponding Author:-Udaykiranraju Kallepalli.

Address:-Junior Resident Department of General Medicine, Siddhartha Medical College, Gunadala, Vijayawada, Andhra Pradesh, India, 305 Prudvi Apartment, Lotus LandMark Sector One, Kedareswarapeta, Vijayawada- 520003, Andhra Pradesh, India. 
On admission, hemodynamics was unstable with gross anemia with tachycardia, breathlessness. Patient was put on oxygen inhalation, 2 units of group compatible, cross matched whole blood was given to stabilize the hemodynamics. Patient was investigated with complete hemogram, prothrombin time and activated partial thromboplastin time were done which were normal. Thyroid function tests were carried out which turned out to be normal. Patient was then investigated with Von Willebrand Factor VWF levels which came positive with low VWF levels $3 \%$ of the normal expected range. Patient was treated with injectable ethamsylate and tranexamic acid. Menorrhagia bleeding subsided and stopped. Following which patient was discharged home with the advice to use oral tranexamic acid to be used during the menstrual flow days. Patient was also advised to use VWF replacement in the form of VWF concentrates or cryoprecipitates rich in VWF prior to surgical procedures, in case of major trauma, tooth extraction or invasive procedures in future.

\section{Case 2:-}

A 15-year-old adolescent boy was brought to emergency room with history of sudden onset of decrease in conscious level with confusion, disorientation following fall from bicycle while riding, with sudden onset of headache following by vomiting after the fall. He was not caught with accident while riding bicycle and he did not ride bicycle on uneven road as might have caused the fall. Prior to this event, he was not suffering from fever, headache, neck pain, photophobia at the time of incident. There was no history of unusual symptoms reported by patient prior to event. Bystanders did not notice loud cry from him prior to event. There was no loss of conscious. There were no abnormal repeated jerking movements of hands, up-rolling of eyes, frothing at mouth, tongue bite, bluish discoloration of face, urine incontinence. The event was not associated with excess sweating. There was past history of recurrent nose bleeds since childhood. Semi-comatose drowsy patient was brought to emergency room.

On examination in emergency room, his vital signs were stable, pupils were equal in size, normal position and briskly reacting to light stimulus. Motor tone examination was normal and superficial and deep tendon reflexes were normal. Immediate CAT scan of brain was undertaken which revealed large intraparenchymal hemorrhage in right temporoparietal lobe with intraventricular extension with mild mass effect and midline shift. Complete hemogram and platelet count were within normal limits. Prothrombin time and International Normalized Ratio(INR) was within normal limits. Activated partial thromboplastin time APTT was prolonged $61.3 \mathrm{sec}$ two times that of the control, $30.0 \mathrm{sec}$.Factor 8, factor 9 and Vonwillebrand factor levels were done. VWF factor levels were $4 \%$ of the expected normal range. Patient was treated with osmotic diuretics,tranexamic acid,ethamsylate injectable. In view of financial constraints, patient could not be treated with VWF factor concentrates. Patient was transferredto higher center with availability of VWF in view of the need of VWF replacement.

\section{Discussion:-}

Von willebrand Disease is a rare inherited autosomalbleeding disease with incidence of symptomatic disease 1 in 1000 population. aPTT can be normal or prolonged depending on the mutation and type of VWD disease. Ristocetin induced platelet aggregation tests will throw light on type of VWD. Pattern of VWF multimers also will help in detecting type of VWD disease. Acquired VWD is a rare disorder, most commonly seen in underlying lymphoproliferative disorders, including monoclonal gammopathies of unknown significance, multiple myeloma and waldenstroms macroglobulinemia. MUGS is seen most commonly in elderly patients. Heydes disease is aortic stenosis with gastrointestinal bleeding attributed to angiodysplasia of the gastrointestinal tract. The shear stress of blood passing through the stenotic valve appears to produce a change in VWF, making it susceptible to serum proteases. Consequently,large multimer forms are lost.

Desmopressin(DDAVP) releases VWF and factor viii from the endothelial stores. It can be used for procedures with minor to moderate risk of bleeding. For major procedures requiring longer periods of normal hemostasis, VWF replacement can be given. Virally inactivated VWF containing factor concentrates are safer than cryoprecipitates as the replacement product.

Antifibrinolytic therapy using either aminocaproic acid or tranexamic acid is an important therapy, either alone or in an adjunctive capacity particularly for the prevention or treatment of mucosal bleeding. These agents are particularly useful in prophylaxis for dental procedures, with DDAVP for dental extraction and tonsillectomy, menorrhagia and prostate procedures. It is contraindicated in the setting of upper urinary tract bleeding due to the risk of ureteral obstruction. 


\section{References:-}

1. Gupta PK, Charan VD, Saxena R. Spectrum of Von Willebrand disease and inherited platelet function disorders amongst Indian bleeders. Annals of hematology. 2007 Jun 1;86(6):403-7.

2. Trasi S, Shetty S, Ghosh K, Mohanty D. Prevalence \& spectrum of von Willebrand disease from western India. Indian Journal of Medical Research. 2005 May 1;121(5):653.

3. Kumar S, Kishore R, Gupta V, Jain M, Shukla J. Prevalence and spectrum of von Willebrand disease in Eastern Uttar Pradesh. Indian Journal of Pathology and Microbiology. 2010 Jul 1;53(3):486.

4. Elayaperumal S, Fouzia NA, Biswas A, Nair SC, Viswabandya A, George B, Abraham A, Oldenburg J, Edison ES, Srivastava A. Type-3 von Willebrand disease in India-Clinical spectrum and molecular profile. Haemophilia. 2018 Nov;24(6):930-40.

5. Kashinkunti MD, Gundikeri SK, Dhananjaya M. A Rare Case of Von Willebrand Disease as a Cause of Menorrhagia Since Menarche: Case Report from Tertiary Care Hospital of North Karnataka. Indian Journal of Public Health Research \& Development. 2015 Apr 1;6(2).

6. Labarque V, Stain AM, Blanchette V, Kahr WH, Carcao MD. Intracranial haemorrhage in von W illebrand disease: a report on six cases. Haemophilia. 2013 Jul;19(4):602-6.

7. Almaani WS, Awidi AS. Spontaneous intracranial hemorrhage secondary to von Willebrand's disease. Surgical neurology. 1986 Nov 1;26(5):457-60.

8. Shih SL, Lin JC, Liang DC, Huang JK. Computed tomography of spontaneous intracranial haemorrhage due to haemostatic disorders in children. Neuroradiology. 1993 Oct 1;35(8):619-21. 